\title{
A CONTABILIDADE COMO INSTRUMENTO DE AUXÍLIO NO CONTROLE DO MEIO AMBIENTE
}

Irene Caires da Silva ${ }^{1}$, Ana Carlina Toni Pereira ${ }^{2}$, Carlile Serafim Pestana ${ }^{2}$, Fernando Henrique Grigoletto dos Santos ${ }^{2}$, Henrique Cesar Garcia ${ }^{2}$, Stella Letícia Aparecida da Silva ${ }^{2}$

${ }^{1}$ Docente da Universidade do Oeste Paulista - UNOESTE. ${ }^{2}$ Discente da Universidade do Oeste Paulista - UNOESTE

\section{RESUMO}

A preservação do meio ambiente nos dias de hoje é uma necessidade e não uma opção devido à grande escassez dos recursos naturais, por isso precisamos conhecer a área contábil e conscientizar da sua importância para o meio ambiente, dessa forma os gestores poderão achar a melhor maneira de utilizar os recursos naturais nas empresas, conscientizando e colaborando com o meio ambiente. Esse trabalho tem como objetivo principal mostrar a conciliação entre a contabilidade fiscal e ambiental nas empresas. Para a execução deste estudo foi realizada uma pesquisa exploratória, para entendermos os processos teóricos que embasam o tema proposto, a partir de pesquisa bibliográfica. Concluindo que a Contabilidade Ambiental é a chave para a sustentabilidade no presente e que as empresas que nesse momento já a aplicam tem mais espaço no mercado, sendo isso uma forte tendência para a atualidade.

PALAVRAS - CHAVE: Contabilidade Ambiental - Meio Ambiente - Responsabilidade Social.

\section{INTRODUÇÃO}

A contabilidade ambiental tem como o estudo do patrimônio ambiental (bens, direitos e obrigações ambientais) das entidades, tendo como objetivo principal fornecer informações sobre os eventos ambientais que modificam a situação patrimonial, e também realizar sua identificação, mensuração e evidenciação.

Dessa forma, ela possui potencial para auxiliar os gestores na tarefa de melhorar a utilização dos recursos naturais, podendo ser usada para demonstrar a responsabilidade ambiental da empresa, através da utilização dos relatórios contábeis onde devem ser evidenciados, de forma transparente, e verdadeira, os gastos com o controle ambiental.

A preservação do meio ambiente nos dias de hoje é uma necessidade e não uma opção, pois os recursos naturais não administrados com certa consciência, rapidamente se tornaram escassos ocorrendo um grande desequilíbrio para gerações futuras. A sociedade precisa se conscientizar de que preservando hoje não faltará amanhã, sendo assim, pessoas físicas e jurídicas precisam rever conceitos e atitudes que possam estar prejudicando o meio ambiente. Sendo assim justifica-se a necessidade de se conhecer a área contábil ambiental e conscientizar da importância necessária ao meio ambiente. 
O presente artigo tem como objetivo principal mostrar que pode ocorrer uma conciliação entre a contabilidade fiscal e ambiental.

Para isso, iremos descrever os conceitos da contabilidade ambiental; demonstrando os impactos causados ao meio ambiente e as vantagens e desvantagens em aplicar a contabilidade ambiental.

Nesse contexto observa-se uma grande dificuldade que as empresas enfrentam em adotar medidas socioambientais, pois, o retorno de seu investimento é alto e vem á longo prazo, mas por outro lado, as empresas que fazem este investimento melhoram a sua imagem no mercado globalizado e acima de tudo conquistam resultados melhores para si próprias.

\section{CONTABILIDADE AMBIENTAL}

A contabilidade ambiental é ainda muito pouco utilizada nas empresas, porém, as questões ambientais, ecológicas e sociais, vêm fazendo com que os contadores e gestores empresariais passem a considerá-las nos sistemas de gestão e contabilidade, dando oportunidade ao reconhecimento da contabilidade ambiental.

Segundo Bergamini Jr.(1999, p.3):

A contabilidade financeira ambiental tem objetivo de registrar as transações da empresa que impactam o meio ambiente e os efeitos das mesmas que afetam, ou deveriam afetar, a posição econômica e financeira dos negócios da empresa, devendo assegurar que:

a) os custos, os ativos e os passivos ambientais estejam contabilizados de acordo com os princípios fundamentais da contabilidade ou, na sua ausência, com as práticas contábeis geralmente aceitas;

b) o desempenho ambiental tenha a ampla transparência de que os usuários da informação contábil necessitam.

Sendo assim podemos definir que contabilidade ambiental serve para registrar as ações das empresas em relação ao meio ambiente, se elas o afetam de maneira negativa ou positiva.

O envolvimento da contabilidade com a questão ambiental pode surgir da realização de gastos com insumos para eliminar ou reduzir pequenos focos ambientais prejudiciais no ambiente empresarial.

Para Costa (2012, p. 54):

Os ativos ambientais representam os estoques dos insumos, peças, acessórios etc, utilizados no processo de eliminação ou redução dos níveis de poluição; os investimentos em máquinas, equipamentos, instalações 
etc, adquiridos ou produzidos com intenção de amenizar os impactos causados ao meio ambiente.

Já para Tinoco e Kraemer (2011, p. 154) “Ativos ambientais são os bens adquiridos pela companhia que têm como finalidade controle, preservação e recuperação do meio ambiente."

Portanto entendemos que Ativo Ambiental são todos os bens da empresa que visam preservação e proteção ao meio ambiente

"Passivo Ambiental é toda obrigação contraída voluntária ou involuntariamente destinada à aplicação em ações de controle, preservação e recuperação do meio ambiente." (COSTA, 2012, p. 67)

"Os passivos ambientais normalmente são contingências formadas em longo período, sendo despercebidos às vezes pela administração da própria empresa." (TINOCO E KRAEMER, 2011, p.155)

Nesse contexto, podemos definir Passivo ambiental como aquele evidencia os gastos que a empresa tem em relação à agressão ao meio ambiente, e consiste no valor gasto para recuperar esses danos. Muitas vezes as empresas não percebem que causaram dano ao meio ambiente e deixam de contabilizar esse gasto.

Para Tinoco e Kraemer (2011) as despesas ambientais podem ser divididas em operacionais e não operacionais. As despesas operacionais são aquelas que ocorrem para o tratamento de resíduos, emissões, restauração, depreciação de equipamentos, entre outras. Em outras palavras, são aquelas que são utilizadas para manter a empresa ambientalmente correta. Já as despesas não operacionais são aquelas que ocorrem fora da atividade principal da empresa, como multa, sanção e compensação de terceiros.

Em relação às receitas ambientais, Costa $(2012$, p. 90) a define como "os recursos auferidos pela entidade, em decorrência da venda de seus subprodutos ou de matéria reciclados."

Portanto as receitas ambientais são aquelas ganhas com as vendas de produtos e prestação de serviços na área ambiental, ou seja, produtos reciclados, prestação de serviços especializados em gestão ambiental e também reduções do consumo de matérias primas, energia e água.

Muitas empresas tem maior ganho devido se preocuparem com o meio ambiente, pois, alguns consumidores dão preferencia a seus produtos do que os de outras empresas que não adotam politicas ambientais. 


\subsection{IMPACTO AMBIENTAL}

Atualmente existem grandes impactos ambientais, devido ao acelerado crescimento econômico, que fez com que o controle com os recursos naturais fossem ignorados, consequentemente a poluição, o consumo de água e energia, tornaram-se excessivos, além de ocupações indevidas na área urbana.

No entanto, o homem está revendo seus conceitos sobre a natureza. Neste sentido, novos comportamentos estão sendo adotados, e proporcionando novas medidas também são exigidas pelo governo.

Assim, os principais poluentes (agente causador do desequilíbrio de um ecossistema) tem inicio com a atividade humana. Sendo a indústria a principal causadora desse efeito, pois ela gera resíduos que prejudicam o meio ambiente.

\subsection{AS VANTAGENS E DIFICULDADES EM APLICAR A CONTABILIDADE AMBIENTAL}

Atualmente percebe-se que o maior desafio ao discutir questões ambientais é relacionar com o crescimento econômico e com a preservação ambiental.

Nesse sentido, RIBEIRO \& MARTINS (1998; p.5) dizem que as demonstrações contábeis podem ser o canal adequado para tais evidências, principalmente porque nelas estão contidas todas as informações pertinentes a situação patrimonial e desempenho da empresa em um determinado período.

Para Tinoco e Kraemer (2011, p. 132), os benefícios da contabilidade ambiental para a indústria são:

- Identificar, estimar, alocar, administrar e reduzir os custos;

- Controlar o uso e os fluxos da energia e dos matérias;

- Da informação mais exata e detalhada para suportar o estabelecimento e a participação em programas voluntários, custos efetivos para melhorar o desempenho ambiental;

Outros exemplos de iniciativas ambientais que se beneficiam da Contabilidade Ambiental de acordo com Tinoco e Kraemer (2011, p. 133), são:

- Prevenção da poluição;

- Projeto para o meio ambiente;

- Calculo dos custos, economias e benefícios de projetos;

- Avaliação de investimentos, cálculo das opções de investimentos;

- Relatório ambiental do desempenho. 
Teoricamente parece ser fácil seu entendimento e sua aplicação, mas na prática são encontradas várias dificuldades as quais impedem o seu uso. A principal delas é a segregação das informações de natureza ambiental das demais informações gerais da empresa, bem como sua correta classificação e avaliação contábil.

Bergamini Júnior (1999, p.4) enumera outros fatores que dificultam o processo de implementação da contabilidade ambiental:

- Ausência de definição clara de custos ambientais;

- Dificuldade em calcular um passivo ambiental efetivo;

- Problema em determinar a existência de uma obrigação no futuro por conta de custos passados;

- Falta de clareza no tratamento a ser dado aos "ativos de vida longa", como por exemplo no caso de uma usina nuclear;

- Reduzida transparência com relação aos danos provocados pela empresa em seus ativos próprios, dentre outros.

\section{METODOLOGIA DA PESQUISA}

Para a execução deste estudo foi realizada uma pesquisa exploratória, para entendermos os processos teóricos que embasam o tema proposto, a partir de pesquisa bibliográfica.

Conforme Gil ( 2002, p. 41):

Pesquisas exploratórias têm como objetivo proporcionar maior familiaridade com o problema, com vista a torná-los mais explícito ou a constituir hipótese. Pode se dizer que estas pesquisas têm como objetivo principal o aprimoramento de idéias ou a descoberta de intuições. Seu planejamento é, portanto, bastante flexível, de modo que possibilite a consideração dos mais variados aspectos relativos ao fato estudado.

Para coleta de dados foi utilizada a técnica bibliográfica, da seguinte forma:

Para Gil (2002, p. 44):

A pesquisa bibliográfica é desenvolvida com base em material já elaborado, constituído principalmente de livros e artigos científicos. Embora em quase todos os estudos já exigido algum tipo de trabalho dessa natureza, há pesquisas desenvolvidas exclusivamente a partir de fontes bibliográficas. As pesquisas sobre ideologias, bem como aquelas que se propõe a análise de diversas posições acerca de um 
problema, também costumam ser desenvolvidas quase exclusivamente mediante fontes bibliográficas.

Portanto, para o desenvolvimento deste trabalho, fizemos pesquisas em livros, sites, revistas e monografias, relacionados ao tema, para compreendermos melhor $\mathrm{o}$ assunto pesquisado.

\section{$4 \quad$ ANÁLISE E DISCUSSÃO DOS RESULTADOS}

A partir de análise bibliográfica de uma série de pesquisas já realizadas publicadas em periódicos percebemos que algumas empresas de variados setores utilizam a Contabilidade Ambiental no processo de tomada de decisão.

Em plena era do movimento sustentável, ainda é pequeno o número de empresas que possuem conhecimentos sobre a Contabilidade Ambiental. Como nosso mundo está passando a se tornar um mundo mais consciente, adotando a Sustentabilidade no seu meio de convívio, é necessário que o Brasil comece a se planejar e executar melhor, para informar e conscientizar a população da importância de se preocupar com o meio ambiente, essa preocupação deve ser tanto para as pessoas, como para as empresas.

Quanto as empresas em que se utilizam de contas especificas para a contabilização de Ativos, Passivos e Custos Ambientais, é visível a dificuldade que possuem em mensurar tais Ativos, Passivos e Custos Ambientais.

Por outro lado, as empresas acreditam a sustentabilidade como uma forte tendência para a atualidade, sendo as mesmas conscientes de que adotando determinadas atitudes no âmbito da Gestão Ambiental teriam mais espaço no mercado.

Conclui-se que a Contabilidade Ambiental é a chave para a sustentabilidade no presente e que as empresas que nesse momento já a aplicam tem mais espaço no mercado, sendo isso uma forte tendência para a atualidade, já que os consumidores estão cada vez mais se preocupando com as ações sociais das empresas, o que elas fazem ou deixam de fazer para preservar o meio ambiente.

\section{REFERÊNCIAS}

COSTA, C.A.G. Contabilidade ambiental: Contabilidade da gestão ambiental. São Paulo. Atlas, 2012.

FERRÃO, R. G. Metodologia científica para iniciantes em pesquisa. 3.ed São Paulo: Atlas , 2003. 
FERREIRA, A.C.S. Contabilidade Ambiental: Uma informação para o desenvolvimento sustentável. 3o ed. São Paulo: Atlas, 2011. p 24-29.

GIL, Antônio Carlos. Como elaborar projetos de pesquisa. 4. ed. São Paulo: Atlas, 2002.

JUNIOR, B.S. Contabilidade e riscos ambientais. Revista do BNDES, Rio de Janeiro: v.6, no 11, junho de 1999.

RICHARDSON, R. J. Pesquisa social: métodos e técnicas. 3.ed. São Paulo: Atlas, 1999.

TINOCO, J.E.P; KRAEMER, M.E.P. Contabilidade e Gestão Ambiental: Gastos, Ativos, Passivos, Despesas (Custos) e Receitas Ambientais. 3ạ edição. São Paulo. Atlas, 2011.

TINOCO, J.E.P; KRAEMER, M.E.P. Contabilidade e Gestão Ambiental: Gestão Ambiental: O que precisamos saber. 3a edição. São Paulo. Atlas, 2011.

VERGARA, S. Projetos e relatórios de pesquisa em administração. 3. ed. São Paulo: Atlas, 2000. 